\title{
A Comparative Study of Attitudes Towards Mental Illness Among Nursing Students
}

\author{
*Dr. C. Radhakanth, **Dr. D. Vijayalakshmi, ***Dr. P. Rahul, \\ ***Dr. K.T.Rajasekhar Reddy \\ * Professor Of Psychiatry, Maharajah's Institute Of Medical Sciences, Vizianagaram \\ * * Professor Of Psychiatry, Government Hospital For Mental Care, Andhra Medical College, Visakhapatnam \\ * **: Postgraduate In Psychiatry, Government Hospital For Mental Care, Andhra Medical College, \\ Visakhapatnam \\ ***: Postgraduate In Psychiatry, Government Hospital For Mental Care, Andhra Medical College, \\ Visakhapatnam
}

\begin{abstract}
Introduction: Nurses play a key role in the treatment and rehabilitation of psychiatric patients. Attitude towards the mentally ill influence the nursing students' choice to take up training and placement in psychiatry as a speciality.

Aim: To study the change in the attitudes among the nursing students towards mental illness after a posting in a tertiary care psychiatric hospital.

MaterialsandMethods: The study was carried out at Government Hospital for Mental Care, a tertiary care psychiatry institute at Visakhapatnam, Andhra Pradesh. 75 nursing students attending psychiatry posting at the time of study who had given informed consent constituted the sample. The student nurses were given Attitude Scale for Mental Illness (ASMI) on the first day (day 1) and on the last day (day 15) of their posting, which included didactic lectures, bedside teaching and ward work. Paired t test was used to calculate the difference in the attitudes between day 1 and day 15.

Results: The nursing students had high scores on negative and positive attitude factors on day 1. On day 15, there was a significant positive change in one of the 5 negative attitude factors, i,e. stereotypism.

Conclusion: Changes in the existing psychiatric training system for nursing students with more focus on shaping a positive attitude towards the mentally ill are required
\end{abstract}

\section{Introduction}

- Psychiatry nurses are an integral component of a multidisciplinary mental health-care team.

- Nurses play a key role in caring for the mentally ill in sickness and in rehabilitating the mentally ill after an episode of illness. According to a World Health organization (WHO) report, there are 0.05 psychiatry nurses per 100,000 people in India ${ }^{1}$. Internationally, the shortage of psychiatry nurses is attributed to negative attitudes of nursing students toward mental illness and the subsequent decision to elect out of psychiatric placements ${ }^{2}$. Such negative attitudes have been shown to have a profound effect on the therapeutic relationships and treatment outcomes ${ }^{3}$. Unfortunately, the universality of harmful beliefs and subsequent negative attitudes toward mentally ill is not in doubt even among nursing students. Students starting the nursing course bring with them stereotypes and prejudice in relation to mentally-ill people, thus showing lack of knowledge as to their possibilities of recovery and social living. Available evidence clearly demonstrates that undergraduate nursing students typically hold unfavourable attitudes toward psychiatric mental health nursing as a career ${ }^{4}$. Further, in view of the severe scarcity of mental health personnel, student nurses should develop a positive attitude toward psychiatric nursing and the mentally ill is more critical in Indian scenario. Very few studies have comprehensively investigated the general attitude of all undergraduate nursing students and looked at the impact of existing psychiatric nursing curriculum in these students ${ }^{5}$. However, limited research is evident in India that examined the student nurses attitudes towards mentally ill. Hence, it is important to understand the existing status of these future nurses to understand what areas need to be addressed. In addition, the present examination system emphasizes on the evaluation of change in knowledge and skill rather than attitudinal change after a prescribed course. Attitudinal change being an important objective of the mental health nursing course.

- In this background, we planned to investigate the attitude of undergraduate nursing students who were studying $2^{\text {nd }}$ year of B.sc nursing, toward people with mental illness. 


\section{Aims And Objectives}

- To study the change in attitudes among nursing students towards mental illness after psychiatry posting in a tertiary care psychiatry hospital.

\section{Materials And Methods}

- The study was carried out at Government Hospital for mental Care, a tertiary care psychiatry institute at Vishakhapatnam, A.P.

- 75 nursing students attending psychiatry posting at the time of the study constituted the sample frame.

- It is a follow up study.

- Their attitudes towards mental illness was assessed using Attitude scale for mental illness on day1 and day 15 i.e. after 15 days of psychiatry posting which includes ward work and teaching classes regarding psychiatric illness and treatment.

- We used a questionnaire-based survey.

- They were explained about the study and voluntary nature of the survey. Additionally, they were assured of the confidentiality and anonymity of the information collected during the study. Those consenting to participate in the study were included in the study.

\section{Attitude scale for mental illness (ASMI)}

- The ASMI-a valid and reliable, self-report measure of attitudes-was administered to students along with a brief demographic form.

- The ASMI section has 34 items and measures the general attitude to mental illness ${ }^{6}$.

- Respondents were given the choice of five response categories to tick based on their feelings from totally disagree to totally agree (totally disagree $=1$, almost totally disagree $=2$, sometimes agree $=3$, almost totally agree $=4$, totally agree $=5$ ) accordingly.

- It consists of six conceptual factors: Benevolence, separatism, stereotyping, restrictiveness, pessimistic prediction and stigmatization.

- Benevolence was intended to measure the paternalistic and sympathetic views of the respondents.

- Separatism: This factor was intended to measure the respondents' attitude of discrimination.

- Stereotyping: This factor was intended to measure the degree of respondents' maintenance of social distance toward the mentally ill. Restrictiveness: This factor was intended to measure viewing the mentally ill as a threat to society.

- Pessimistic prediction is the negative evaluative component toward the mentally ill. This factor was intended to measure the level of prejudice toward mental illness.

- Stigmatization is the feeling of disgrace or discredit, which sets a person apart from others. This factor was intended to measure the discriminatory behaviour of the students toward mental illness.

\section{Statistics}

- The data were analysed using SPSS ver 21.

- The level of statistical significance was kept at $P<0.05$ for all the tests.

- $\quad$ Paired student $t$ test was used to calculate the differences between day 1 and day 15 .

\section{Results}

- The sample consisted of 75 nursing students.

- On day 1 nursing students had high scores on negative attitudes factors like separatism(31.3), stereotypism (15.9), restrictiveness(11.8), pessimistic prediction(12.8), stigmatisation (11.7), and they had high scores on positive attitudes domains like benevolence.

- On day 15 , there was a significant positive change in one of the five negative attitude factors i.e. setreotypism (14.35). 


\begin{tabular}{|l|l|l|l|}
\multicolumn{2}{l}{ Paired sample t-test } \\
\begin{tabular}{|l|l|l|l|}
\hline \multicolumn{1}{|c|}{ MEAN } & STANDARD DEVIATION & P VALUE \\
\hline Seperatism 1 & 31.31 & 7.50 & 0.300 \\
Seperatism 15 & 32.33 & 4.69 & \\
\hline Stereotypism 1 & 15.92 & 2.99 & $\mathbf{0 . 0 0 3}$ \\
Stereotypism 15 & 14.43 & 2.93 & \\
\hline Restrictiveness 1 & 11.8 & 4.49 & 0.810 \\
Restrictiveness 15 & 11.65 & 2.90 & 0.986 \\
\hline Benevolence 1 & 26.77 & 4.60 & 0.897 \\
Benevolence 15 & 26.79 & 3.40 & \\
\hline Pessimistic prediction 1 & 12.89 & 3.35 & 0.677 \\
Pessimistic prediction 15 & 12.96 & 2.51 & \\
\hline Stigmatization 1 & 11.71 & 3.15 & \\
Stigmatization 15 & 11.48 & 3.12 & \\
& & & \\
\hline
\end{tabular}
\end{tabular}

\section{Discussion}

This study was novel in its attempt to examine the student nurses attitudes toward mental illness who were enrolled into the nursing profession. Very few studies in India investigated student nurses attitudes towards mental illness ${ }^{7}$.However, these studies mainly focused on comparing the effectiveness of the mental health course on attitudinal change toward mentally ill. However it is critical to examine the attitudes of student nurses toward mentally ill before their mental health nursing course, which will be introduced to them during the psychiatry posting ${ }^{10-16}$. The present study used a standardized questionnaire that measures the multi dimensions. Thus, this multidimensional scale helps us identify both the negative and positive aspects of the attitudes where we can work on to intervene, reinforce and enhance the attitudes of nursing students to provide holistic care to persons with mental illness. In the present study, the results showed that nursing students have significant positive attitudes toward mental illness in one of the six attitudes factors: Benevolence, and high negative attitudes in five of the six attitude factors on day 1. Higher scores on the negative domains of the scale indicated an overall unhealthy attitude of nursing students toward those with mental illness.

On day 15 i.e. after 15 days of psychiatry posting which includes ward work and teaching classes regarding psychiatric illness, there was a significant positive change in stereotypism factor. However still nursing students had higher scores on remaining negative attitude factors. Higher benevolence scores indicated that most of the Nursing students would express kindness and altruism toward the person suffering from any form of mental illness. These findings were congruent with previous research ${ }^{8,9}$. The participants showed more restrictive attitude toward mentally ill as they rated high to the statements in restrictiveness domain. These findings indicated nursing students agreed that mentally ill people cannot enjoy personal or social life events such as marriage, working, having children, or family.

Unfortunately, nursing students had more stigmatizing attitudes toward people with mental illness. Nursing students had negative attitudes in separatism, stereotype and pessimistic predictions domains as they rated high. Students starting the Nursing Course bring with them stereotypes and prejudice in relation to mentally-ill people, thus showing lack of knowledge as to their possibilities of recovery and social living ${ }^{10}$.

In line with a previous study findings, nursing students had a negative attitude when it came to accepting the autonomy and independence of the mentally ill and in considering them as part of the larger unaffected community ${ }^{11}$. As in most societies, stereotypes about mental illness, such as an influence of evil spirits, religious afflictions and deviations from societal norms, were also rated high by these students. Further, they had pessimistic attitude regarding recovery, rehabilitation of mentally ill patients. This study has shown that negative attitudes of undergraduate nursing students toward psychiatric illness are amenable to appropriate psychiatric training. The role of theoretical teaching in shaping the attitudes of nursing students toward psychiatry has also been established. However, in the absence of appropriate exposure to mental health-care training, the undergraduate nursing students are likely to pass school with their stereotype, negative perception of mental health care intact ${ }^{17}$.

Hence, it seems imperative to make necessary changes to the existing nursing curriculum. This would help improve the attitude of the nursing students toward psychiatry ${ }^{18}$.

\section{Limitatiions}

- The present study has certain limitations that include

- Small sample size made difficult to draw conclusions.

- However, it would be useful to conduct similar research among students after completing academic education in this area and perhaps comparing the students from other than nursing disciplines to see if there are any similarities and/or differences in the results.

- As with every other investigation, participants may not have been precisely accurate in answering the questionnaires. 


\section{Conclusion}

The present study showed the nursing students have positive attitudes toward mental illness in one of the six attitudes factors: Benevolence, however, these students have negative attitudes in separatism, stereotype and pessimistic predictions, restrictiveness, stigmatisation domains as they rated high on day 1 . However on day 15 there was a significant positive change in the stereotype domain. These findings have important implications for nursing training. They demonstrate the need for specifically focusing training to target the students with the most negative attitudes. Thus, academic education from courses in this area must be planned so as to favour the change of the attitudes that include greater use of teaching strategies that challenge beliefs and assumptions and promote a commitment to provide holistic care to people with mental illness.

\section{References}

[1]. Geneva: World Health Organization; 2005. WHO. Mental Health Atlas 2005.

[2]. Cutliffe JR. The differences and commonalities between United Kingdom and Canadian Psychiatric/Mental Health Nursing: A personal reflection. J Psychiatr Ment Health Nurs. 2003;10:255-7.

[3]. Hoencamp E. 'Yes doctor, no doctor': What do patients want from you? Acta Psychiatr Scand.1999;100:319-20.

[4]. Happell B, Gough Nee Hayman-White K. Undergraduate nursing students' attitudes towards mental health nursing: Determining the influencing factors. Contemp Nurse. 2007;25:72-81.

[5]. Kumakura N, Ito H, Mori T, Saito T, Kurisu E, Asaka A, et al. Attitude change towards mental illness during nursing education A cross-cultural study of student nurses in Korea, Republic of China and Japan.Asia Pac J Public Health. 1992;6:120-5.

[6]. $\mathrm{Ng} \mathrm{P}$, Chan KF. Sex differences in opinion towards mental illness of secondary school students in Hong Kong. Int J Soc Psychiatry. 2000;46:79-88

[7]. Luke BJ. Bangalore: Department of Nursing, Rajiv Gandhi University of Health Sciences; 2006. Comparative study to assess the attitude towards mental illness between second year and fourth year Bsc Nursing students in selected colleges in Mangalore.

[8]. Avanci Rde C, Malaguti SE, Pedrão LJ. Authoritarianism and benevolence towards mental illness: Study with beginning a nursing program. Rev Lat Am Enfermagem. 2002;10:509-15.

[9]. Lingeswaran A. Psychiatric curriculum and its impact on the attitude of Indian undergraduate medical students and interns. Indian J Psychol Med. 2010;32:119-27.

[10]. Pedrão LJ, Avanci Rde C, Malaguti SE. Profile of undergraduate nursing students' attitudes towards mental disease, before the influence of specific academic education. Rev Lat Am Enfermagem.2002;10:794-9.

[11]. Surgenor LJ, Dunn J, Horn J. Nursing student attitudes to psychiatric nursing and psychiatric disorders in New Zealand. Int J Ment Health Nurs. 2005;14:103-8.

[12]. Pedrão LJ, Galera SA, Silva MC, Cazenave Gonzalez A, Costa ML, Júnior, Souza MC, et al. Attitudes of graduate nursing students towards mental disorders in Brazil, Chile and Peru. Rev Lat Am Enfermagem.2005;13:339-43.

[13]. Laugharne R, Appiah-Poku J, Laugharne J, Shankar R. Attitudes toward psychiatry among final-year medical students in kumasi, ghana. Acad Psychiatry. 2009;33:71-5.

[14]. Madianos MG, Priami M, Alevisopoulos G, Koukia E, Rogakou E. Nursing students' attitude change towards mental illness and psychiatric case recognition after a clerkship in psychiatry. Issues Ment Health Nurs. 2005;26:169-83

[15]. Halter MJ. Perceived characteristics of psychiatric nurses: Stigma by association. Arch Psychiatr Nurs.2008;22:20-6.

[16]. Gouthro TJ. Recognizing and addressing the stigma associated with mental health nursing: A critical perspective. Issues Ment Health Nurs. 2009;30:669-76.

[17]. Romem P, Anson O, Kanat-Maymon Y, Moisa R. Reshaping students' attitudes toward individuals with mental illness through a clinical nursing clerkship. J Nurs Educ. 2008;47:396-402.

[18]. Yamauchi T, Semba T, Sudo A, Takahashi N, Nakamura H, Yoshimura K, et al. Effects of psychiatric training on nursing students' attitudes towards people with mental illness in Japan. Int J Soc Psychiatry.2011;57:574-9. 